Eixo Temático: Processos de Ensino-Aprendizagem

\title{
ET-06-002 \\ AS CONCEPÇÕES DOS ESTUDANTES DO ENSINO FUNDAMENTAL SOBRE O CONCEITO DE FECUNDAÇÃO HUMANA: UMA RELAÇÃO CONHECIMENTOS PRÉVIO E CÍRCULO HERMENÊUTICO-DIALÉTICO
}

Maria Emanuelle Tenório Ayres de Souza ${ }^{1}$, Ana Kelly Batista dos Santos ${ }^{1}$, Beranice dos Santos Sena ${ }^{1}$, Ricardo Ferreira das Neves ${ }^{2}$

${ }^{1}$ Graduandas em Licenciatura em Ciências Biológicas UFPE/CAV. E-mail: pixasmanu@outlook.com.

²Professor do Núcleo de Ciências Biológicas UFPE/CAV.

http://dx.doi.org/10.21472/congrebio2016.et-06-002

\section{RESUMO}

A pesquisa teve como objetivo analisar as concepções dos alunos do ensino fundamental sobre o conceito de fecundação humana, por meio da relação entre o conhecimento prévio e o círculo hermenêutico-dialético. A fecundação humana representa um processo fundamental para compreensão da fisiologia do sistema reprodutor masculino e feminino, além das possibilidades de estudos sobre sexualidade e doenças relacionadas ao sexo. A compreensão dos estudantes sobre o conceito foi subsidiada pela Teoria da Aprendizagem Significativa (TAS) por meio de seus conhecimentos prévios e ressignificada através do método do Circulo Hermenêutico Dialético (CHD) através de um consenso coletivo. Percebemos que em sua maioria, os estudantes apresentaram lacunas conceituais com emprego de terminologias não adequadas ao Ensino de Ciências e focaram no conceito diretamente ao seu processo final. A sinergia entre a TAS e o CHD potencializou a (re)construção do conceito em estudo e permitiu novo vislumbramento dos estudantes sobre a importância da fecundação para a perpetuação das espécies e especificamente, a humana.

Palavras-chave: Fecundação; Conhecimento prévio; Círculo hermenêutico-dialético.

\section{INTRODUÇÃO}

Os Parâmetros Curriculares Nacionais (PCN) de Ciências Naturais para os anos finais do Ensino Fundamental apontam alguns aspectos para o entendimento do processo reprodutivo de todas as formas de vida, destacando a existência, por exemplo, de gametas como células reprodutivas e o meio de fecundação (interno ou externo) dos indivíduos que utilizam a reprodução sexuada como forma de perpetuação das espécies (BRASIL, 1998).

Nesse sentido, o conceito de fecundação nesses documentos oportunizam discussões sobre a reprodução humana e as questões sobre sexualidade, sendo necessário que o estudante compreenda a importância da existência de dois tipos básicos de fecundação e considerar a diversidade de seres vivos em que alguns grupos são capazes de realizar apenas uma delas, enquanto outros realizam os dois tipos. Também, que algumas espécies se utilizam da reprodução assexuada e/ou sexuada, sendo que essa última, a partir da união do gameta masculino com o feminino, como ocorre nos seres humanos.

Ainda, nesse enfoque, muitos conceitos relacionados à área da embriologia animal, como no caso da fecundação humana, por vezes é apresentado ao estudante de forma fragmenta, sem possíveis ramificações a serem exploradas e trabalhadas, direcionando ao estudante um viés muito reducionista, visto que partir do conceito em tela é possível haver desmembramentos relacionados a outros temas como à sexualidade e doenças relacionadas ao sexo. 
Visando à compreensão do conceito de fecundação pelos estudantes é importante que haja uma interação e valorização do senso comum, visto que essa compreensão prévia deve ser considerada para uma possível reconstrução conceitual, o que nos reporta as perspectivas da Teoria da Aprendizagem Significativa (TAS) de David Paul Ausubel, destacando a importância da valoração do sendo comum no processo de aprendizagem, pois considera o que o aluno já sabe como ponto chave para aprendizagem de novos conceitos (AUSUBEL; NOVAK; HANESIA, 1980). Assim, a aprendizagem terá sentido quando o professor valorizar os conhecimentos pré-existentes dos estudantes.

Nesse sentido, aportado à aprendizagem significativa buscamos compreensão do sentido do conceito de fecundação mediante os discursos proferidos pelos sujeitos, que para fomentar esse momento, elencamos a aplicação do Círculo Hermenêutico-Dialético (CHD), um método de pesquisa qualitativa proposto por Egon Guba e Yvonna Lincoln, o qual discorre sobre a avaliação de quarta geração e se utilizam da técnica do CHD (GUBA; LINCOLN, 1989). Esse método representa uma ferramenta interativa que possibilita aos sujeitos envolvidos uma ressignificação de conceitos (NEVES, 2006).

Para tanto, a nossa problemática norteia a seguinte pergunta: quais as concepções prévias dos estudantes do Ensino Fundamental sobre o conceito de fecundação humana? Assim, a pesquisa está aportada na Teoria da Aprendizagem Significativa (TAS) utilizando os conhecimentos prévios e no método do Círculo Hermenêutico-Dialético (CHD) para (re)construção do conceito de fecundação e acreditamos que essa relação teórico-metodológica pode proporcionar uma sinergia significativa e trazer contribuições relevantes para a pesquisa no Ensino de Ciências.

\section{OBJETIVO}

A pesquisa teve como objetivo analisar as concepções dos alunos do ensino fundamental sobre o conceito de fecundação humana, por meio da relação entre o conhecimento prévio e o círculo hermenêutico-dialético.

\section{O CONCEITO DE FECUNDAÇÃO NO ENSINO FUNDAMENTAL}

A fecundação representa uma sequência de eventos moleculares que é iniciado com o contato entre um espermatozoide e um ovócito e termina com a mistura dos cromossomos de ambas as células, na metáfase da primeira divisão mitótica do zigoto (MOORE e PERSAUD, 2008). Alguns termos que aparecem no conceito de divisão celular, como "cromossomos", "metáfase” e "mitose”, não aparecem no currículo de Ciências do Ensino Fundamental, como aponta Brasil (1998). Na Biologia no Ensino Médio, o tema é abordado com mais profundidade, em conjunto com conteúdos na área da sexualidade, corroborando com o que Brasil (2000) orienta. Para tanto, considerando a necessidade de conteúdos mais direcionados ao seu nível cognitivo dos estudantes no Ensino Fundamental, os Parâmetros Curriculares Nacionais (PCN), apontam a necessidade de destacar aspectos fundamentais a serem trabalhados nesse nível de ensino em relação ao tema fecundação, como a especialização de células para reprodução ou gametas (espermatozoides e óvulos) e ênfase no processo de fecundação interna, principalmente na espécie humana, focando no processo como a reunião de gametas para formação da célulaovo (BRASIL, 1998). Noutro momento, os temas ligados ao sexo são extremamente relacionados à natureza humana e por isso, necessitam ser explorado desde cedo, sendo a escola um veículo condutor corroborando com formações e reflexões aos indivíduos, visando ao esclarecimento de conceitos e um conhecer melhor da sua sexualidade (SOUSA, 2006). Assim, a abordagem do tema "fecundação humana" e de outras temáticas relacionadas ao sexo e a sexualidade possibilita ações sobre a saúde física, psicológica e social dos sujeitos. Também, corroborando, o Ministério da Educação recomenda que sejam abordados temas relacionados à educação sexual como puberdade, ciclo menstrual e ovulatório fisiologia geral do sistema reprodutor na Educação Básica, o que inclui os processos de fecundação (BRASIL, 2010). 


\section{A TEORIA DA APRENDIZAGEM SIGNIFICATIVA: ALGUMAS CONSIDERAÇÕES}

A Teoria da Aprendizagem Significativa (TAS) surgiu a partir das perspectivas de David Ausubel tendo o conhecimento prévio como base para a construção de um conhecimento científico mais significativo (AUSUBEL et al., 1980). Na TAS, “o fator isolado mais importante que influencia a aprendizagem é aquilo que o aluno já sabe” (MOREIRA, 1999, p. 152). Assim, o conhecimento prévio representa base para que a aprendizagem se desenvolva de forma significativa e não meramente mecânica.

O processo de aprendizagem significativa ocorre a partir de conceitos pré-existentes na estrutura cognitiva do aprendiz e se relaciona com os novos conceitos apresentados possibilitando a ampliação de seu conhecimento, ou seja, permite que o novo conhecimento seja ancorado ao pré-existente dando lhe sentido (MOREIRA, 1999). Assim, quando o aluno está pré-disposto a aprender, as novas informações se relacionam com os conhecimentos prévios de forma efetiva e permite que a aprendizagem seja duradoura.

Dessa forma, o conteúdo deve ser apresentado de forma lógica e clara permitindo a conexão com o novo conteúdo. Não obstante, a aprendizagem mecânica faz com que as novas informações permaneçam soltas, sem um significado efetivo, promovendo um esquecimento em longo prazo.

\section{O CÍRCULO HERMENÊUTICO-DIALÉTICO (CHD): POSSIBILIDADE DE (RE)CONSTRUÇÃO INDIVIDUAL E COLETIVA}

O Círculo Hermenêutico-Dialético (CHD) representa um método qualitativo de coleta de dados proposto por Guba e Lincoln (1989), o qual utiliza elementos da hermenêutica (mediação, acordo e unidade de sentido) e da dialética (diálogos, críticas, análises, construções e reconstruções individuais e coletivas) procurando um consenso próximo da realidade estudada (NEVES, 2006; NEVES et al., 2012).

Para Barbosa (2001), essa relação hermenêutico-dialética possibilita à compreensão textual, da fala e do depoimento resultantes de um processo social, com significados específicos, mas articulados entre si. Assim, o CHD atua como uma ferramenta que viabiliza o diálogo, a reflexão e as discussões possibilitando os sujeitos analisarem os seus pontos de vista por diferentes olhares (NEVES, 2006; NEVES et al., 2012).

A dinâmica do círculo consiste em entrevistar os sujeitos pesquisados de maneira sequenciada e sistemática coletando as construções teóricas individuais do primeiro ao último, possibilitando que cada um dos envolvidos possa observar as construções teóricas individuais dos outros sujeitos, tendo oportunidade de alterar ou não suas. Isso se repete até que o último aluno seja entrevistado, finalizando o círculo (NEVES, 2006; NEVES et al., 2012). Na Figura 1, a seguir, temos uma ilustração da dinâmica do CHD.

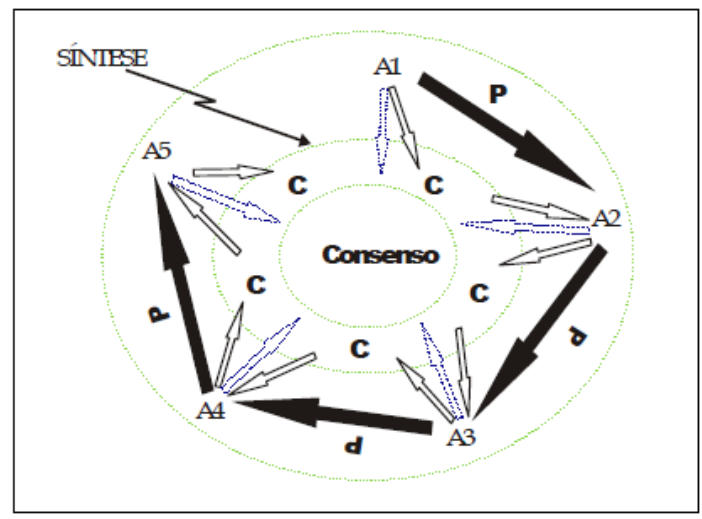

Figura 1. Ilustração do Círculo Hermenêutico-Dialético. Fonte: Neves (2006, p. 56). 
Na Figura 1, no primeiro círculo, temos o grupo de alunos entrevistados, no segundo, a dinâmica do "vai-e-vem" das construções e reconstruções teóricas e no terceiro (centro); exposição de comentários e construção de uma nova concepção, isso representa um encontro final com todos os entrevistados, buscando um consenso único, o do grupo (NEVES, 2006; NEVES et al., 2012).

Nesse contexto, podemos entender a hermenêutica como uma ferramenta interessante para o entendimento de mundo, pois permite uma gama de possibilidades, promovendo buscar a troca de experiências dos atores sociais e do investigador, entendendo as observações feitas por cada sujeito. Enquanto, na dialética, a promoção de construções e reconstruções coletivas desses sujeitos.

\section{METODOLOGIA}

A pesquisa foi realizada junto a nove estudantes do $8^{\circ}$ Ano do Ensino Fundamental numa escola municipal, em Pombos-PE. A coleta dos dados foi feita com base nos conhecimento prévios dos estudantes, partindo das premissas da TAS e como aporte norteador, foi utilizando o CHD.

Primeiramente, realizamos uma abordagem sobre o conceito de fecundação humana, a partir da TAS, no resgate dos conhecimentos prévios dos estudantes, o quais responderam a uma arguitiva individualmente: O que você compreende sobre fecundação humana? Aqui, captamos o entendimento dos estudantes sobre o conceito e passamos para a etapa seguinte que seria a aplicação do CHD. Ressaltamos que devido ao CHD ser bastante complexo, quando abordado em todas as etapas, ou seja, teríamos de mobilizar tempo extraclasse para concluir todo o processo, optamos apenas por trabalharmos, nesse momento, apenas a etapa de consenso.

Posteriormente, para a aplicação do CHD, os estudantes de forma aleatória se dividiram em dois grupos (quatro e cinco integrantes). Nesse momento, foi solicitado aos grupos que a partir de seu conhecimento prévio individual (construções teóricas), lessem e discutissem sobre as ideias apresentada por cada integrante e após isso, formassem uma concepção única sobre o conceito estudado (consenso). Essas perspectivas estão apontadas na seção subsequente.

\section{RESULTADOS E DISCUSSÃO}

Primeiramente, foram analisadas as construções iniciais de cada estudante e posteriormente, as construções coletivas do grupo, conforme o Quadro 1.

Em linhas gerais, os estudantes do grupo I possuem um conhecimento ainda em construção conceitual. Isso é percebido, quando determinam o processo final, mas não expressam claramente o que seria de fato o conceito.

No que concerne, as considerações dos estudantes, o E1 apontou que a fecundação estaria relacionada com a gravidez, como também nas colocações do E2 e E3, embora estes discorram para uma visão mais construtiva do conceito, formulando uma relação do esperma com o óvulo, mas ainda enfocam o resultado final. Neles, observamos a terminologia "esperma" em vez de "espermatozoide” e "óvulo" em vez de gameta feminino. Também, o E4 define a fecundação como o "ato de fecundar”, uma resposta muito vaga e pontual.

No que concerne ao momento do consenso, observamos uma melhor organização das ideias, mas ainda com permanência de obstáculos de aprendizagem por meio de terminologia não adequadas ao conteúdo ou ideias muito vagas. Contudo, isso era de se esperar, pois os estudantes estão num nível de desenvolvimento cognitivo com relação a sua série no Ensino Fundamental e muitos conceitos e ideias ainda estão a serem estruturadas. 
Quadro 1. Construções dos alunos sobre o conceito de Fecundação Humana (Grupo I e II).

\begin{tabular}{|c|c|c|c|c|c|c|c|}
\hline $\mathrm{G}$ & $\mathbf{E}$ & CI & $\mathrm{CG}$ & G & $\mathbf{E}$ & CI & $\mathrm{CG}$ \\
\hline \multirow{6}{*}{ I } & El & $\begin{array}{l}\text { "A mulher pode } \\
\text { ficar grávida." }\end{array}$ & \multirow{6}{*}{$\begin{array}{l}\text { "A mulher pode } \\
\text { ficar grávida } \\
\text { quando o esperma } \\
\text { chegar no óvulo } \\
\text { ou com a } \\
\text { fecundação do } \\
\text { esperma." }\end{array}$} & \multirow{6}{*}{ II } & El & $\begin{array}{l}\text { "Fecundação é } \\
\text { quando o esperma } \\
\text { entra no óvulo." }\end{array}$ & \multirow{6}{*}{$\begin{array}{l}\text { "Fecundação } \\
\text { é a união } \\
\text { entre os } \\
\text { gametas } \\
\text { masculino e } \\
\text { feminino } \\
\text { que resulta } \\
\text { na formação } \\
\text { da célula- } \\
\text { ovo, a } \\
\text { primeira } \\
\text { célula que } \\
\text { vira um } \\
\text { novo ser." }\end{array}$} \\
\hline & \multirow[t]{2}{*}{ E2 } & \multirow[t]{2}{*}{$\begin{array}{l}\text { "A mulher pode } \\
\text { ficar grávida } \\
\text { quando o esperma } \\
\text { chegar no óvulo." }\end{array}$} & & & E2 & $\begin{array}{l}\text { "Fecundação é } \\
\text { quando o bebê está } \\
\text { sendo formado." }\end{array}$ & \\
\hline & & & & & E3 & "Fecundação é a & \\
\hline & \multirow[t]{2}{*}{ E3 } & \multirow{2}{*}{$\begin{array}{l}\text { "Fecundação é a } \\
\text { mulher que fica } \\
\text { grávida quando o } \\
\text { esperma chegar no } \\
\text { óvulo." }\end{array}$} & & & & $\begin{array}{c}\text { união entre gametas } \\
\text { masculino e } \\
\text { feminino." }\end{array}$ & \\
\hline & & & & & E4 & $\begin{array}{l}\text { "Fecundação é o que } \\
\text { resulta na formação, } \\
\text { a primeira célula-ovo } \\
\text { que vira um novo } \\
\text { ser." }\end{array}$ & \\
\hline & E4 & "É fecundar." & & & E5 & $\begin{array}{l}\text { "Fecundação é o } \\
\text { órgão feminino." }\end{array}$ & \\
\hline
\end{tabular}

Legenda: G=grupo; E=estudantes; CI=concepção individual; CG=concepção do grupo.

Aqui ressaltamos a evidencia da relação concepção prévia e CHD, pois as informações apresentadas sobre o conceito puderam ser revisadas por todos do grupo, mesmo não havendo uma confluência entre os sujeitos que permitissem melhor sofisticação epistemológica no resultado final, pois a concepção individual e a expressividade dos sujeitos determinam a construção teórica final do consenso, fato já apontado pelos estudos de Neves (2006), aqui presente nos discursos dos E2 e E3, em relação aos outros estudantes.

No que concerne ao grupo II, em geral, às concepções dos estudantes se apresentaram num conhecimento mais próximo das perspectivas científicas, de forma que são apresentadas terminologias mais específicas, o que avança além da série e nível que se encontram, diferentemente do grupo anterior, como exemplo os gametas, mesmo que confundido com outras terminologias, antes do processo final.

Quanto aos estudantes E1, E3 e E4, estes apresentaram uma concepção de fecundação bastante estruturada apontando o esperma/gametas entrar no óvulo/célula-ovo. Isso demonstra que se possuem conhecimento da presença de células para haver o processo final. Aqui ressaltamos que o uso de terminologia bem avançada (célula-ovo) pelo E4, demonstra o nível de conhecimento desse estudante, em que essa terminologia "célula-ovo" corrobora com as discussões e conteúdos para o Ensino Fundamental, apontados e enfatizados nos Parâmetros Curriculares Nacionais (PCN) para essa série (BRASIL, 1998).

Os estudantes E2 e E5 apontam, respectivamente, que a fecundação seria o ato de gerar vida, ou seja, uma inclinação apenas para o processo final, muito relacionado ao grupo anterior. Também explicita que seria relativo a um tipo de órgão feminino, o que está fora do contexto científico.

Ao consenso do grupo, este se destacou por conseguir apontarem terminologias bastante relevantes para o nível de ensino no qual se encontra, como "gametas" e "célula-ovo", esta última corrobora com as perspectivas de Moore e Persaud (2008), em que a "célula-ovo" faz referencia ao zigoto.

Por fim, ao analisarmos as construções iniciais dos dois grupos podemos perceber que existe uma construção do conceito de fecundação mais fragilizada no grupo I em relação ao II, pois o primeiro apresenta ideias mais direcionadas ao processo final, do que para a sua formação. 
Os estudantes E1 e E4 do Grupo I apresentam respostas bastante similares com as construções individuais dos estudantes E1 e E5 do Grupo II, confundindo "esperma” com "espermatozoide" e direcionando a fecundação apenas a fecundar.

Em se tratando do consenso de ambos os grupos, o conceito chegou perto da realidade. Os estudantes do grupo I mostraram debilidade na construção do consenso em grupo, onde confundiram termos e não mostraram clareza no conceito final. Já os estudantes do Grupo II, trouxeram terminologias mais específicas da área e relacionadas com o conceito em estudo.

\section{CONCLUSÕES}

A fecundação é um momento de extrema importância para a perpetuação das mais variadas espécies e não apenas da espécie humana, mas o seu entendimento é ainda deficiente entre os alunos, pois em sua maioria a fecundação estaria relacionada apenas a reprodução humana, não perpassando essa ideia, mesmo considerando as perspectivas dos Parâmetros Curriculares Nacionais, apontando significativa necessidade de esclarecimentos nesse nível de ensino.

Percebemos que em sua maioria, os estudantes apresentaram lacunas conceituais com emprego de terminologias não adequadas para o Ensino de Ciências e focaram no conceito diretamente ao seu processo final.

No que concerne à proposta de Ausubel, a TAS oportunizou importância do conhecimento prévio como ponto de partida para possível reconstrução de novos conhecimentos, deixando claro que as novas informações são compreendidas a partir da conexão com aquelas pré-existentes na estrutura cognitiva do aluno. Já ao CHD, permitiu que a interação entre indivíduos, pudesse reconstruir novas ideias, por meio do diálogo e da discussão coletiva.

A sinergia entre a TAS e o CHD potencializou a (re)construção do conceito em estudo e permitiu novo vislumbramento dos estudantes sobre a importância da fecundação para a perpetuação das espécies e especificamente, a humana.

\section{REFERÊNCIAS}

BRASIL. Parâmetros curriculares nacionais: Ciências Naturais. Secretaria de Educação Fundamental. Brasília: MEC/SEF, 1998.

BRASIL, Secretaria de Educação Fundamental. Parâmetros Curriculares Nacionais: Ciências da Natureza, Matemática e suas Tecnologias. Brasília: MEC/SEF, 2000.

BRASIL. Saúde e Educação. Ministérios da Saúde e da Educação. Portaria no 196-A, de 9 de abril de 2010. Diário Oficial da União, $1^{\text {a }}$ sessão, 9 de abril de 2010.

BARBOSA, R. H. S. Mulheres, reprodução e aids: as tramas da ideologia na assistência à saúde de gestantes HIV+. São Paulo: Escola Nacional de Saúde Pública, 2001. (Tese de doutorado).

GUBA, E.; LINCOLN, Y. S. Fourth generation evaluation. Newbury Park: Sage, 1989.

MOREIRA, M. A. Teorias de aprendizagem. São Paulo: EPU, 1999.

MOORE, K. L.; PERSAUD, T. V. N. Embriologia Básica. 7 ed. São Paulo: Elsevier, 2008.

NEVES, R. F. A interação do Ciclo da Experiência de Kelly com o Círculo HermenêuticoDialético para a Construção de Conceitos de Biologia. Recife: Universidade Federal Rural de Pernambuco, 2006. (Dissertação de mestrado). 
NEVES, R. F.; CARNEIRO-LEÃO, A. M. A.; FERREIRA, H. S. A interação do ciclo da experiência de Kelly com o círculo hermenêutico-dialético, para a construção de conceitos de biologia. Ciênc. educ., v. 18, n. 2, p. 335-352, 2012.

SOUSA, A. M. G. Aparelho reprodutor - concepções e obstáculos de aprendizagem em crianças do $1^{\circ}$ CEB: um estudo de caso em meio urbano. Minho, Portugal: Universidade do Minho, 2006. (Dissertação de Mestrado). 